Cite this: RSC Adv., 2017, 7, 44890

Received 28th July 2017

Accepted 12th September 2017

DOI: $10.1039 / c 7 r a 08354 h$

rsc.li/rsc-advances
Check for updates

\section{A Zn based metal organic framework nanocomposite: synthesis, characterization and application for preconcentration of cadmium prior to its determination by FAAS $\uparrow$}

\begin{abstract}
Zahra Nazari, ${ }^{a}$ Mohammad Ali Taher ${ }^{\mathrm{a}}$ and Hamid Fazelirad (D) *b
A new metal-organic framework (MOF) with zinc as the metal ion and benzene-1,3-dicarboxylic acid as organic linker was synthesized via the hydrothermal method and used as a selective nanoadsorbent for the extraction and preconcentration of trace amounts of cadmium via a solid phase extraction method. Also, flame atomic absorption spectrometry was applied for the quantification of extracted Cd ions. The synthesized Zn-MOF nanocomposite was characterized by different techniques such as transmission electron microscopy, scanning electron microscopy, $\mathrm{X}$-ray diffraction spectrometry and Fourier transform infrared spectroscopy. Furthermore, the effects of various factors on the synthesis of the $\mathrm{Zn}$ MOF nanoadsorbent and $\mathrm{Cd}$ adsorption process were investigated. Under the optimum conditions, a preconcentration factor of 100 , RSD of $2.2 \%$ for $80.0 \mu \mathrm{g} \mathrm{L}{ }^{-1} \mathrm{Cd}$ and detection limit of $0.2 \mu \mathrm{g} \mathrm{L}^{-1}$ were obtained. Finally, the recommended method was applied for the determination of $\mathrm{Cd}$ ions in real and standard samples.
\end{abstract}

\section{Introduction}

In the last two decades, metal-organic frameworks (MOFs), also known as porous coordination polymers (PCPs), have emerged as a new category of porous and crystalline materials. ${ }^{1}$ They have diverse unique properties such as great internal surface area (Langmuir surface area of $10000 \mathrm{~m}^{2} \mathrm{~g}^{-1}$ ), ultra-high porosity (up to $90 \%$ free volume) and application in the design of inorganic and organic components. ${ }^{2}$ Due to these fascinating features, MOFs have different applications in diverse fields such as sensing, ${ }^{3,4}$ separation and storage, ${ }^{5,6}$ drug delivery, ${ }^{7,8}$ batteries, ${ }^{9}$ adsorption, ${ }^{10}$ catalysis $^{11,12}$ and proton conduction. . $^{\mathbf{1 3 4}}$

As mentioned, MOFs have various unique properties and advantages, but they have some disadvantages such as low chemical stability. This weakness prevents the use of MOFs' properties with maximum potential, but there are different functional groups and compounds that can be combined with MOFs to improve their weaknesses. ${ }^{15-17}$

In our industrial world, heavy metal pollution in our environment has been studied. Heavy metal pollution has intense effects on human health due to its non-biodegradable property,

\footnotetext{
${ }^{a}$ Department of Chemistry, Shahid Bahonar University of Kerman, Kerman, Iran ${ }^{b}$ Young Researchers and Elite Club, Yazd Branch, Islamic Azad University, Yazd, Iran. E-mail: hamidfazelirad@gmail.com; Fax: +98-3433221452; Tel: +98-3433221452

$\dagger$ Electronic supplementary information (ESI) available. See DOI: 10.1039/c7ra08354h
}

high water solubility and high potential for accumulation in human and animal bodies. Most of these metals are carcinogenic and damages different parts of the body, such as nerves, bones and liver and can interfere with regular operation of several vital enzymes. ${ }^{18}$ Among these hazardous elements, cadmium is one of the most well-known toxic species even at very low concentration. It can enter the body via water and food chain and damage different vital systems such as immune system, nervous system, digestive system and reproductive system. ${ }^{19}$ For this reason, different separation and determination techniques were utilized to monitor the cadmium concentration levels in diverse environmental, biological and agricultural samples. ${ }^{20-22}$

One of the important applications of metal-organic frameworks, is separation of materials, gases and compounds. By using of the modified MOFs, diverse gases, organic and inorganic compounds were separated such as $\mathrm{H}_{2} / \mathrm{CO}_{2},{ }^{23} \mathrm{Xe}$ and $\mathrm{Kr},{ }^{24}$ $\mathrm{CO}_{2} / \mathrm{N}_{2} / \mathrm{CH}_{4},{ }^{25} \mathrm{~Pb},{ }^{26}$ hemoglobin ${ }^{27}$ and etc. As can be seen, most of separation procedures with metal-organic frameworks, were carried out about gases and organic compounds. Based on our knowledge, there is no previous work about the synthesis of zinc based metal-organic framework (Zn-MOF) and application for cadmium separation and determination.

The aim of this study is the synthesis of Zn-MOF nanotrate of trace amounts of cadmium via SPE prior to its quantification by flame atomic absorption spectrometry. The synthesized Zn-MOF nanoadsorbents will be characterized by particles via hydrothermal method to extract and preconcen- 
SEM, XRD, TEM and FT-IR techniques. Also, adsorption isotherms, kinetic and thermodynamic studies will be performed and discussed. Finally, the important factors about the synthesis of Zn-MOF nanoparticles and adsorption procedure of Cd ions will be investigated and optimized.

\section{Experimental}

\subsection{Reagents and materials}

The cadmium standard solution $\left(1000.0 \mathrm{mg} \mathrm{L}^{-1}\right)$ was prepared by dissolving the appropriate quantity of $\mathrm{Cd}\left(\mathrm{NO}_{3}\right)_{2}$ (Merck, Germany) in deionized water. Working standard solutions of Cd were prepared at different concentrations via diluting the stock solution with deionized water. Zinc nitrate, benzene-1,3dicarboxylic acid $\left(\mathrm{C}_{8} \mathrm{H}_{6} \mathrm{O}_{4}\right)$, hydrochloric acid, sodium hydroxide and ethanol were prepared from Merck (Germany). Also, deionized water was used in all experiments and dilutions.

\subsection{Apparatus}

Cadmium determinations were done by application of a Varian (Spectra AA 220, USA) flame atomic absorption spectrometer. Xray diffraction (XRD) images were recorded with a PANalytical apparatus (X'Pert ${ }^{3}$, Germany). A Philips transmission electron microscope (TEM) (EM-208, USA) and Carl-Zeiss scanning electron microscope (SEM) (EVO-40, Germany) were applied to study the morphological structure. Also, FT-IR spectra were prepared with a Bruker spectrometer (Tensor-27, England). Some other apparatus such as Memmert oven (Germany), Zak Shimi magnetic stirrer (Iran), Shimi Gostar autoclave (Iran), Ohaus digital balance (Switzerland) and Fater Electronic shaker-incubator (Iran) were applied.

\subsection{Synthesis of $\mathrm{Zn}$ based metal-organic framework nanocomposite}

To synthesis the Zn-MOF nanoparticles, hydrothermal method was selected and applied. A $2.78 \mathrm{~g} \mathrm{Zn}\left(\mathrm{NO}_{3}\right)_{2}$ and $0.63 \mathrm{~g}$ benzene1,3-dicarboxylic acid (as organic linker) were transferred into two separate beakers (B1: $\mathrm{Zn}\left(\mathrm{NO}_{3}\right)_{2}$ and B2: benzene-1,3dicarboxylic acid) and a mixed solvent containing $30 \mathrm{~mL}$ deionized water and $10 \mathrm{~mL}$ ethanol was added to each beaker. Beaker 1 was stirred at $50{ }^{\circ} \mathrm{C}$ for $15 \mathrm{~min}$ to dissolve zinc nitrate. Then, the contents of beaker 2 were added to beaker 1 and stirred at $50{ }^{\circ} \mathrm{C}$ for $30 \mathrm{~min}$. This beaker was transferred into an oven and heated at $150{ }^{\circ} \mathrm{C}$ for $8 \mathrm{~h}$. After sedimentation of yellow precipitates, the supernatant solution was decanted and the synthesized Zn-MOF nanocomposites were washed with deionized water and ethanol for several times until removal of the impurities. The final precipitates were dried in an oven at $50{ }^{\circ} \mathrm{C}$ for $5 \mathrm{~h}$.

2.3.1 Effect of temperature and time on the $\mathrm{Zn}$-MOF structure. To synthesis the Zn-MOF nanoparticles with uniform size and distribution, the effect of temperature and time in hydrothermal method was studied. The prepared sample solutions were heated under different conditions in an oven and the SEM images of the synthesized Zn-MOF nanoparticles were prepared: (1) $150{ }^{\circ} \mathrm{C}$ for $6 \mathrm{~h}$ (Fig. S1a $\dagger$ ), (2) $150{ }^{\circ} \mathrm{C}$

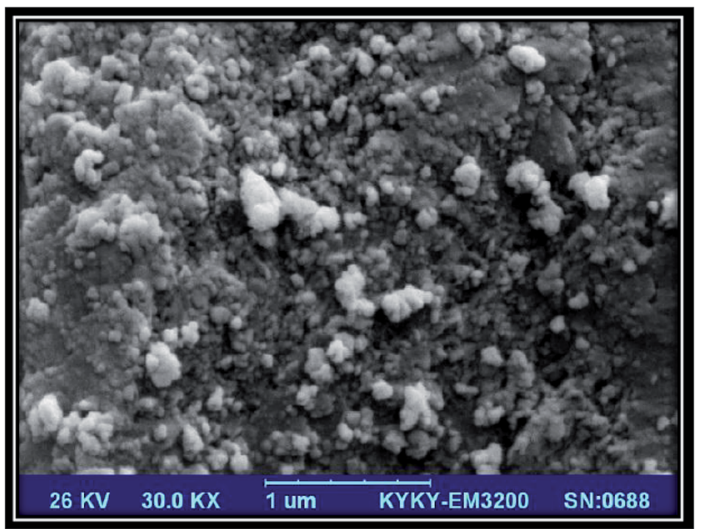

Fig. 1 SEM images of Zn-MOF nanoparticles in optimum synthesis conditions: $200{ }^{\circ} \mathrm{C}$ for $8 \mathrm{~h}$.

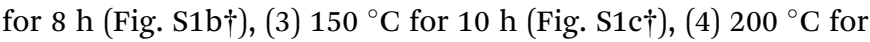
$4 \mathrm{~h}$ (Fig. S1d †), (5) $200^{\circ} \mathrm{C}$ for $6 \mathrm{~h}$ (Fig. S1e†) and (6) $200^{\circ} \mathrm{C}$ for $8 \mathrm{~h}$ (Fig. 1). As can be seen, by increasing the heating temperature and time, the size of the obtained nanoparticles was decreased and their separation from each other was increased. As you can see in Fig. 1, by increasing the temperature to $200{ }^{\circ} \mathrm{C}$ and time to $8 \mathrm{~h}$, nucleation process was increased dramatically and $\mathrm{Zn}$ MOF nanoparticles have the best separation and least size. So, heating process at $200{ }^{\circ} \mathrm{C}$ for $8 \mathrm{~h}$ was selected as the best condition for Zn-MOF synthesis.

\subsection{TEM study}

Transmission electron microscopy is a useful tool to study the nano-sized materials. By application of this technique, high quality images can be prepared from the crystalline species to obtain beneficial information about the size and crystallography of nanomaterials. TEM image of the synthesized Zn-MOF nanoparticles was shown in Fig. 2. As can be seen, the synthesized Zn-MOF nanoadsorbents have pore size less than $50 \mathrm{~nm}$.

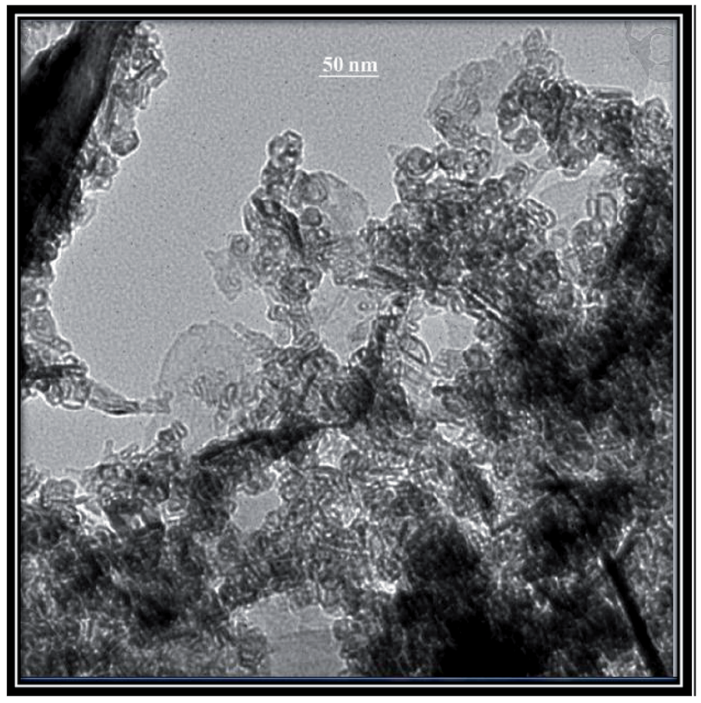

Fig. 2 TEM image of the synthesized Zn-MOF nanoparticles. 


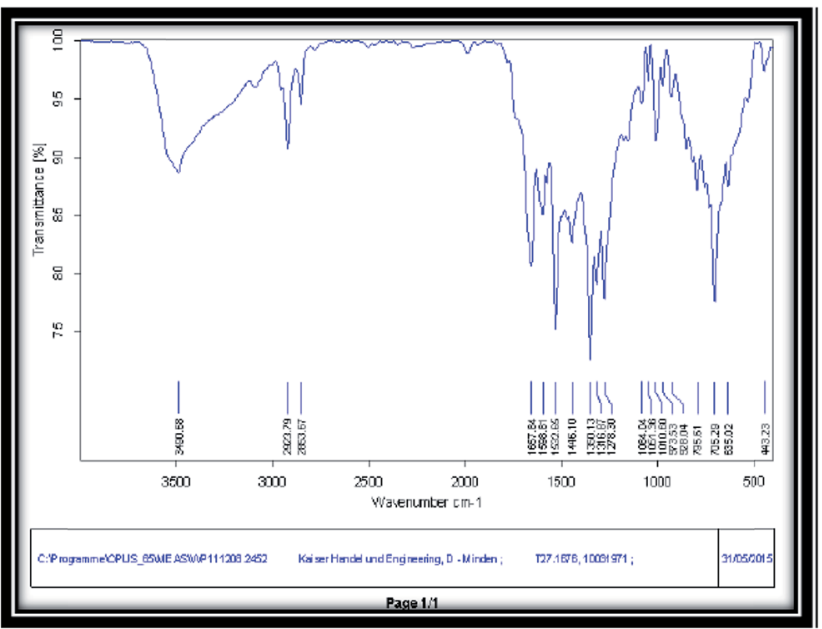

Fig. 3 FT-IR spectrum of the synthesized Zn-MOF nanoparticles.

\section{$2.5 \quad$ FT-IR}

To identify the organic compounds and functional groups in different materials, FT-IR is an effective technique. Fig. 3 shows FT-IR spectrum of Zn-MOF nanoparticles after calcination at $300{ }^{\circ} \mathrm{C}$ for $3 \mathrm{~h}$ in $\mathrm{KBr}$ matrix. As depicted, there is no peak due to impurities and preliminary reagents and it demonstrates the completion of the reaction. Also, various peaks were presented such as $400-1000 \mathrm{~cm}^{-1}$ for $\mathrm{Zn}-\mathrm{O}$ bonds, $3000-3600 \mathrm{~cm}^{-1}$ for $\mathrm{OH}$ of carboxylic acid, $1667.64 \mathrm{~cm}^{-1}$ for $\mathrm{C}=\mathrm{O}$ stretching bond and $1446.10 \mathrm{~cm}^{-1}$ and $1568.31 \mathrm{~cm}^{-1}$ for confirming the aromaticity of structure.

\subsection{XRD studies}

By application of XRD technique, substantial information can acquire including crystal structure, phase type and product purity. XRD pattern for the synthesized Zn-MOF nanoparticles was shown in Fig. 4. As you can see, all peaks are distinct. Also,

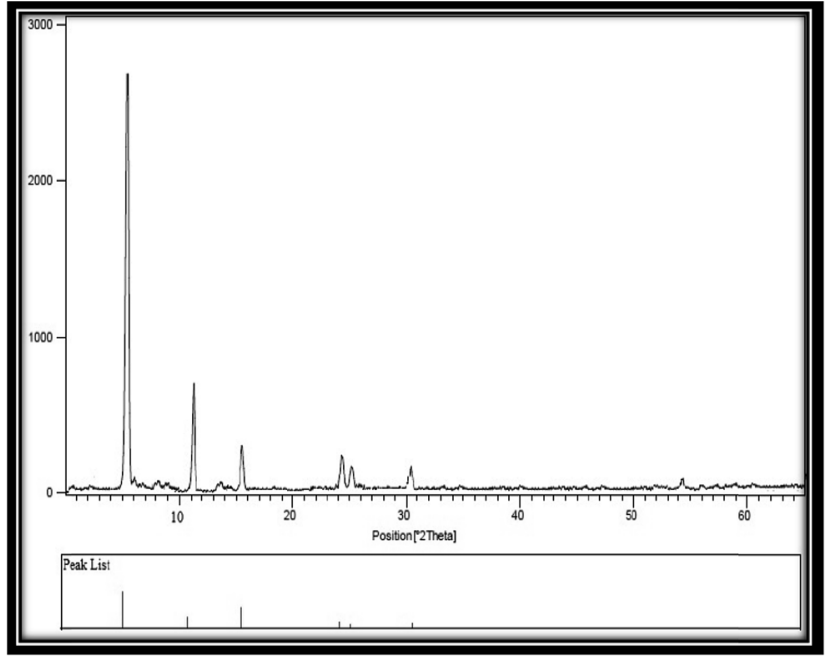

Fig. 4 XRD pattern of the synthesized Zn-MOF nanoparticles. there is no peak because of the impurities. Sharp peaks in this spectrum corroborate the crystalline structure of Zn-MOF nanoparticles. By using of Debye-Scherrer equation, the average size of the synthesized Zn-MOF nanoparticles was estimated as $40-50 \mathrm{~nm}$.

\subsection{Cadmium adsorption}

A $0.4 \mathrm{~g}$ Zn-MOF nanoadsorbent was weighed and transferred into a $100 \mathrm{~mL}$ beaker containing $20 \mathrm{~mL} 80.0 \mu \mathrm{g} \mathrm{L}^{-1}$ cadmium solution and its pH was adjusted to 4.0. By using of a shakerincubator instrument, temperature and time of stirring were adjusted at $25{ }^{\circ} \mathrm{C}$ and $60 \mathrm{~min}$, respectively. After finalization of the preconcentration procedure, Zn-MOF nanoadsorbents were separated from the sample solution via centrifugation for $10 \mathrm{~min}$ at $3000 \mathrm{rpm}$. The concentration of the remained $\mathrm{Cd}$ in the sample solution was quantified via flame atomic absorption spectrometer. The quantity of the adsorbed cadmium with $\mathrm{Zn}$ MOF nanoadsorbent was calculated from the difference between the initial and final Cd concentrations in the sample solution.

\section{Results and discussion}

\subsection{Optimization of the preconcentration process}

After synthesis and characterization of Zn-MOF nanoadsorbents, various important extraction factors including $\mathrm{pH}$, nanoadsorbent quantity, temperature and time of stirring stage were investigated and optimized. Meanwhile, all experiments were performed three times.

3.1.1 Effect of $\mathbf{p H}$. For investigation of the $\mathrm{pH}$ effect on the adsorption recovery of $\mathrm{Cd}, 20 \mathrm{~mL}$ solution containing $80.0 \mu \mathrm{g}$ $\mathrm{L}^{-1}$ cadmium was prepared in the $\mathrm{pH}$ range of 2 to 8 . The acquired results (Fig. 5) showed that the extraction process was done quantitatively in the $\mathrm{pH}$ range of $3-4$. So, $\mathrm{pH}=4.0$ was chosen as the optimum $\mathrm{pH}$ in further experiments.

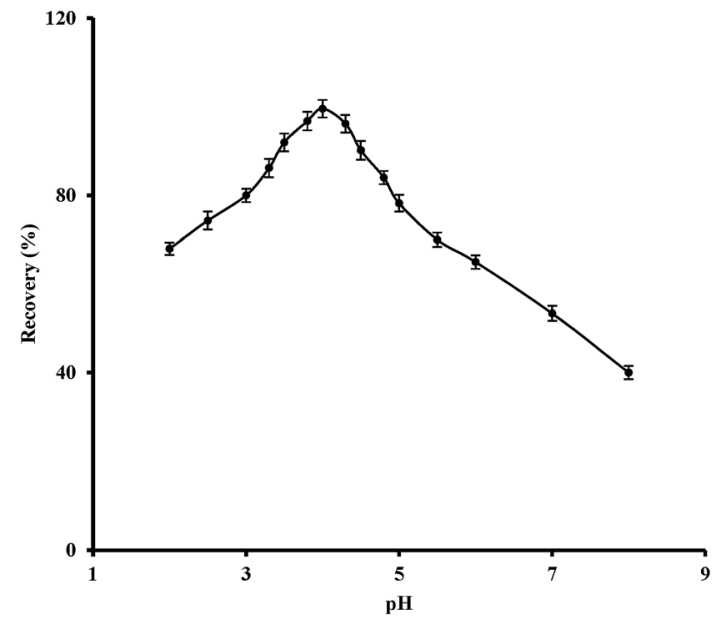

Fig. 5 The $\mathrm{pH}$ effect on the extraction recovery of cadmium. Experimental conditions: amount of $\mathrm{Zn}-\mathrm{MOF}$ nanoadsorbent: $0.4 \mathrm{~g}, \mathrm{Cd}$ concentration: $80.0 \mu \mathrm{g} \mathrm{L}^{-1}$, volume of sample solution: $20 \mathrm{~mL}$, temperature: $25^{\circ} \mathrm{C}$, contact time: $60 \mathrm{~min}$, centrifugation time: $10 \mathrm{~min}$. 
3.1.2 Nanoadsorbent amount. $20 \mathrm{~mL}$ sample solution containing $80.0 \mu \mathrm{g} \mathrm{\textrm {L } ^ { - 1 }}$ cadmium was prepared and after $\mathrm{pH}$ adjustment at $\mathrm{pH}=4.0$, the extraction procedure was done by using different quantities of $\mathrm{Zn}-\mathrm{MOF}$ nanoadsorbent from 0.1 to $0.6 \mathrm{~g}$. The acquired results showed that with enhancement of the Zn-MOF nanoadsorbent quantity from 0.1 to $0.4 \mathrm{~g}$, the adsorption efficiencies were increased and remained constant for more amounts. So, $0.4 \mathrm{~g} \mathrm{Zn}$-MOF was chosen as the optimum amount of nanoadsorbent for all experiments.

3.1.3 Stirring time. In all SPE methods, the solid phase needs to sufficient contact time in sample solution for quantitative adsorption of analyte(s). Various contact times between 0 to 180 min were studied and the acquired results showed the maximum Cd adsorption recovery at $60 \mathrm{~min}$ and longer stirring times. Therefore, $60 \mathrm{~min}$ was selected as the minimum contact time with quantitative extraction of Cd by using of the synthesized Zn-MOF nanoadsorbents.

3.1.4 Temperature. To study the temperature effect on the adsorption efficiency of cadmium ions with the synthesized nanoparticles, the extraction procedure was done in different temperatures from 25 to $60^{\circ} \mathrm{C}$. Based on the obtained data, in higher temperatures than $25{ }^{\circ} \mathrm{C}$, the extraction recoveries were decreased. This means that the cadmium adsorption on the surface of Zn-MOF nanoadsorbents is an exothermic process. So, $25{ }^{\circ} \mathrm{C}$ was used throughout the experiments.

\subsection{Thermodynamic investigations}

Temperature has a significant role in adsorption procedures. Adsorption process of cadmium ions via $\mathrm{Zn}$-MOF nanoparticles was investigated via thermodynamic studies in various temperatures (Table 1). The acquired Van't Hoff equation for cadmium adsorption by application of the synthesized Zn-MOF nanoadsorbent is: $Y=-7045.3 x+22.843$ with correlation coefficient $R^{2}=0.8362$. In this equation, the slope and intercept are enthalpy and entropy, respectively. The negative amount of enthalpy confirms that the Cd adsorption is an exothermic procedure. Also, the negative amount of Gibbs free energy $\left(\Delta G=-13852.1 \mathrm{~kJ} \mathrm{~mol}^{-1}\right)$ confirms that the cadmium adsorption was done spontaneously. As you can see in Table 1, Gibbs free energies were reduced with increasing the temperature. Also, the positive figure of entropy $\left(\Delta S=22.9 \mathrm{~kJ} \mathrm{~mol}^{-1}\right)$ shows increasing the disorders in the cadmium adsorption on the active sites of $\mathrm{Zn}-\mathrm{MOF}$ nanoadsorbents.

Table 1 Thermodynamic studies of $\mathrm{Cd}$ adsorption via $\mathrm{Zn}-\mathrm{MOF}$ nanoadsorbent

\begin{tabular}{llll}
\hline$T\left({ }^{\circ} \mathrm{K}\right)$ & $\Delta H\left(\mathrm{~kJ} \mathrm{~mol}^{-1}\right)$ & $\Delta S\left(\mathrm{~kJ} \mathrm{~mol}^{-1}\right)$ & $\Delta G\left(\mathrm{~kJ} \mathrm{~mol}^{-1}\right)$ \\
\hline 298 & -7045.3 & 22.9 & -13852.1 \\
303 & & & -13852.5 \\
308 & & & -13966.5 \\
313 & & & -14081.0 \\
323 & & -14194.7 \\
333 & & & -14433.2
\end{tabular}

Table 2 Acquired data from the adsorption isotherms

\begin{tabular}{lllll}
\hline Langmuir model & $q_{\mathrm{m}}\left(\mathrm{mg} \mathrm{g}^{-1}\right)$ & $K_{\mathrm{L}}\left(\mathrm{L} \mathrm{mg}^{-1}\right)$ & $R^{2}$ & \multicolumn{2}{l}{$R_{\mathrm{L}}$} \\
& 14.47 & 0.1494 & 0.9984 & 0.0025 \\
\hline \multirow{2}{*}{ Temkin model } & \multirow{2}{*}{$\left(\mathrm{L} \mathrm{mg}^{-1}\right)$} & $B$ & $R^{2}$ \\
& 21.97 & 0.2637 & 0.8414 \\
\hline \multirow{2}{*}{ Freundlich model } & $K_{\mathrm{f}}\left(\left(\mathrm{mg} \mathrm{g}^{-1}\right)\left(\mathrm{L} \mathrm{g}^{-1}\right) n\right)$ & $n$ & $R^{2}$ \\
& 0.0516 & 0.4139 & 0.9072 \\
\hline
\end{tabular}

\subsection{Adsorption isotherms}

To describe the behavior of Zn-MOF nanoadsorbent in cadmium adsorption, Langmuir, Freundlich and Temkin adsorption isotherms were studied (Table 2). As can be seen, the acquired data show that the Langmuir model $\left(R^{2}=0.9984\right)$ fitted better than the Temkin model $\left(R^{2}=0.8414\right)$ and Freundlich model $\left(R^{2}=0.9072\right)$. Also, the highest cadmium adsorption capacity for Zn-MOF nanoadsorbent was obtained as $14.47 \mathrm{mg} \mathrm{g}^{-1}$.

\subsection{Kinetic studies}

To study of adsorption kinetic of Cd on the surface of the synthesized Zn-MOF nanoadsorbent, two equations including pseudo-first-order and pseudo-second-order were investigated. Based on the acquired data, the adsorption kinetic of cadmium ions has more correlation with pseudo-second-order $\left(R^{2}=\right.$ $0.993)$ in comparison with pseudo-first-order $\left(R^{2}=0.0171\right)$. This confirms that the cadmium adsorption process was done via van der Waals forces and sharing the electrons between the Cd ions and Zn-MOF nanoadsorbents.

\subsection{Performance characteristics}

Under the optimized conditions, the detection limit based on $3 s_{\mathrm{b}} / m$ (where $s_{\mathrm{b}}$ is the standard deviation of the blank signals $(\sim 0.018)$ and $m$ is the slope of the calibration curve after extraction) was $0.2 \mu \mathrm{g} \mathrm{L} \mathrm{L}^{-1}$ in the original solution. Also the relative standard deviation (RSD) for seven replicate solid phase extractions of $80.0 \mu \mathrm{g} \mathrm{L}^{-1} \mathrm{Cd}$ was $2.2 \%$. Furthermore, the preconcentration factor was calculated as 100 .

\subsection{Analytical applications}

In order to establish the validity of the procedure, the proposed method was applied for the extraction of cadmium in a water sample. The reliability of the method was checked by the analysis of the sample spiked with the known amount of Cd. The results illustrated in Table 3 reveal that the recovery of spiked sample at $95 \%$ confidence level is satisfactory.

To verify the accuracy of the method, this procedure was also applied for the determination of $\mathrm{Cd}$ in a certified reference material; SRM 1643d trace elements in water and the analytical results are given in Table 4 . As can be seen, the obtained results are in good agreement with the reference values and there is no significant difference between the results and the accepted values. Thus, the procedure is reliable for the analysis of a wide range of samples. 
Table 3 Determination of $\mathrm{Cd}$ in water sample

\begin{tabular}{lcll}
\hline Sample $\left(\mu \mathrm{g} \mathrm{L}^{-1}\right)$ & Spiked & Found $^{a}$ & Recovery (\%) \\
\hline Tap water $^{b}$ & 0.0 & N.D. & - \\
& 50.0 & 48.2 & $96.4 \pm 2.1$
\end{tabular}

${ }^{a}$ Mean \pm standard deviation $(n=3) .{ }^{b}$ Kerman drinking water, Kerman, Iran. ${ }^{c}$ N.D. not detected.

Table 4 Determination of $\mathrm{Cd}$ in certified reference material

\begin{tabular}{|c|c|c|c|}
\hline Sample & Composition & Found $^{a}$ & $\begin{array}{l}\text { Recovery } \\
(\%)\end{array}$ \\
\hline $\begin{array}{l}\text { SRM 1643d } \\
\text { trace elements } \\
\text { in water }\end{array}$ & $\begin{array}{l}\mathrm{Li} ; 16.50, \mathrm{Be} ; 12.53, \mathrm{~B} ; 144.8, \\
\mathrm{Na} ; 22.07, \mathrm{Mg} ; 7.989, \mathrm{Al} ; \\
\text { 127.6, K; 2.356, Ca; 31.04, V; } \\
\text { 35.1, Cr; 18.53, Mn; 37.66, Fe; } \\
\text { 91.2, Co; 25.00, Ni; 58.1, Cu; } \\
\text { 20.5, Zn; 72.48, As; 56.02, Se; } \\
\text { 11.43, Sr; 294.8, Mo; } 112.9, \mathrm{Ag} ; \\
\text { 1.270, Tl; 7.28, Sb; 54.1, Ba; } \\
\text { 506.5, Pb; 18.15, Cd; } 6.47 \mu \mathrm{g} \mathrm{L}^{-1}\end{array}$ & 6.31 & $97.5 \pm 2.5$ \\
\hline
\end{tabular}

Table 5 Comparison of the proposed method with other reported $\mathrm{Cd}$ determination methods

\begin{tabular}{lllll}
\hline Analysis method & $\mathrm{EF}^{a}$ or $\mathrm{PF}^{b}$ & $\mathrm{RSD}(\%)$ & $\mathrm{LOD}\left(\mu \mathrm{g} \mathrm{L}^{-1}\right)$ & Ref. \\
\hline FAAS & 20 & $<10$ & 0.9 & 28 \\
FAAS & 94 & 1.0 & 0.25 & 29 \\
FAAS & 200 & 6.4 & 0.2 & 30 \\
FAAS & 67 & $<4.1$ & 2.4 & 31 \\
FAAS & 100 & $<1.5$ & 0.18 & 32 \\
FAAS & 14 & $2.92-3.38$ & 0.23 & 33 \\
FAAS & - & 8.2 & 0.5 & 34 \\
FAAS & 100 & 3 & 0.42 & 35 \\
FAAS & $\mathbf{1 0 0}$ & $\mathbf{2 . 2}$ & $\mathbf{0 . 2}$ & This work
\end{tabular}

${ }^{a}$ Enrichment factor. ${ }^{b}$ Preconcentration factor.

\subsection{Comparison with the other methods}

Table 5 compares the characteristic data of the investigated method with the other reported methods for the determination of cadmium in diverse samples. The recommended method has wide linear dynamic range, high preconcentration factor and high sensitivity. Also, the proposed method has the highest enhancement factor except one case ${ }^{30}$ and the lowest detection limit except only one. ${ }^{32}$

\section{Conclusion}

In the present work, Zn-MOF nanoparticles were synthesized via hydrothermal method, characterized using SEM, XRD, TEM and FT-IR and applied for the extraction and preconcentration of cadmium ions. Also, the adsorption isotherms, thermodynamic and kinetic studies were performed. Besides considerably high preconcentration ability, some other benefits of the system were enhancement of FAAS sensitivity, environmentally-friendly property, low limit of detection, its simplicity and speed of analysis. Furthermore, the proposed method permits effective separation and preconcentration of $\mathrm{Cd}$ and final determination by FAAS. Finally, the applicability of the suggested adsorbent and method was investigated in real and certified reference materials.

\section{Conflicts of interest}

There are no conflicts of interest to declare.

\section{References}

1 J. Huang, G. Fang, K. Liu, J. Zhou, X. Tang, K. Cai and S. Liang, Chem. Eng. J., 2017, 322, 281-292.

2 H.-C. Zhou, J. R. Long and O. M. Yaghi, Chem. Rev., 2012, 112, 673-674.

3 G. W. Xu, Y. P. Wu, W. W. Dong, J. Zhao, X. Q. Wu, D. S. Li and Q. Zhang, Small, 2017, 13, 1602996.

4 K. Tomar, M. Gupta and A. K. Gupta, Inorg. Chem. Commun., 2016, 64, 16-18.

5 S. Zhang, D. Li, S. Chen, X. Yang, X. Zhao, Q. Zhao, S. Komarneni and D. Yang, J. Mater. Chem. A, 2017, 5, 12453-12461.

6 C.-X. Yang, Y.-Z. Zheng and X.-P. Yan, RSC Adv., 2017, 7, 36297-36301.

7 A. R. Chowdhuri, D. Bhattacharya and S. K. Sahu, Dalton Trans., 2016, 45, 2963-2973.

8 M. X. Wu and Y. W. Yang, Adv. Mater., 2017, 29, 1606134.

9 H.-J. Peng, G.-X. Hao, Z.-H. Chu, Y.-W. Lin, X.-M. Lin and Y.-P. Cai, $R S C A d v .$, 2017, 7, 34104-34109.

10 R. Krishna, $R S C A d v .$, 2017, 7, 35724-35737.

11 K. D. Nguyen, S. H. Doan, A. N. V. Ngo, T. T. Nguyen and N. T. S. Phan, J. Ind. Eng. Chem., 2016, 44, 136-145.

12 R. Li, Y. Jiang, J. Zhao, D. Ramella, Y. Peng and Y. Luan, RSC Adv., 2017, 7, 34591-34597.

13 X. Wang, T. Qin, S.-S. Bao, Y.-C. Zhang, X. Shen, L.-M. Zheng and D. Zhu, J. Mater. Chem. A, 2016, 4, 16484-16489.

14 N. Sikdar, D. Dutta, R. Haldar, T. Ray, A. Hazra, A. J. Bhattacharyya and T. K. Maji, J. Phys. Chem. C, 2016, 120, 13622-13629.

15 Q. Zhou, M. Lei, J. Li, Y. Liu, K. Zhao and D. Zhao, Microchim. Acta, 2017, 184, 1029-1036.

16 C. Gong, X. Zeng, L. Xin, J. Zhang and J. Xie, RSC Adv., 2017, 7, 36860-36866.

17 X. Wang, X. Liu, H. Rong, Y. Song, H. Wen and Q. Liu, RSC Adv. , 2017, 7, 29611-29617.

18 H. Fazelirad and M. A. Taher, Environ. Technol., 2016, 37, 300-307.

19 T. Kemper and S. Sommer, Environ. Sci. Technol., 2002, 36, 2742-2747.

20 N. A. Kasa, D. S. Chormey, Ç. Büyükpınar, F. Turak, T. B. Budak and S. Bakırdere, Microchem. J., 2017, 133, 144-148. 
21 A. Thongsaw, W. C. Chaiyasith, R. Sananmuang, G. M. Ross and R. J. Ampiah-Bonney, Food Chem., 2017, 219, 453-458.

22 L. Della Puppa, M. Komárek, F. Bordas, J.-C. Bollinger and E. Joussein, J. Colloid Interface Sci., 2013, 399, 99-106.

23 H. R. Abid, H. Tian, H.-M. Ang, M. O. Tade, C. E. Buckley and S. Wang, Chem. Eng. J., 2012, 187, 415-420.

24 S.-J. Lee, K. C. Kim, T.-U. Yoon, M.-B. Kim and Y.-S. Bae, Microporous Mesoporous Mater., 2016, 236, 284-291.

25 A. Chakraborty, S. Roy, M. Eswaramoorthy and T. K. Maji, J. Mater. Chem. A, 2017, 5, 8423-8430.

26 N. Yin, K. Wang, L. Wang and Z. Li, Chem. Eng. J., 2016, 306, 619-628.

27 X. Yao, X. Ma, X. Gao and L. Jia, $R S C A d v .$, 2017, 7, 2933029338.

28 Ș. Saçmacı and Ș. Kartal, Clean: Soil, Air, Water, 2011, 39, 577-583.
29 Ş. Saçmacı and M. Saçmacı, J. AOAC Int., 2016, 99, 10581065.

30 Ş. Saçmacı, Ş. Kartal and M. Saçmacı, Int. J. Environ. Anal. Chem., 2012, 92, 1626-1637.

31 Ş. Saçmacı, Y. Yılmaz, Ş. Kartal, M. Kaya and F. Duman, Biol. Trace Elem. Res., 2014, 159, 254-262.

32 S. Sacmaci, S. Kartal, M. Sacmaci and C. Soykan, Bull. Korean Chem. Soc., 2011, 32, 444-450.

33 L. A. Meira and F. de Souza Dias, Microchem. J., 2017, 130, 56-63.

34 M. Firat, S. Bakırdere, M. S. Findıkoğlu, E. B. Kafa, E. Yazıcı, M. Yolcu, Ç. Büyükpınar, D. S. Chormey, S. Sel and F. Turak, Spectrochim. Acta, Part B, 2017, 129, 37-41.

35 M. Tuzen, S. Sahiner and B. Hazer, Food Chem., 2016, 210, 115-120. 